\title{
Successful removal of 36 fibroids from a uterus: case report
}

\author{
Temesgen Tilahun Bekabil* \\ Assistant Professor of Obstetrics and Gynecology, College of Medical and Health Sciences, Wollega University, Nekemte, Ethiopia
}

\begin{abstract}
This case is presented to show that multiple fibroids, as many as 36 , can be effectively removed by following meticulous surgical steps of myomectomy.
\end{abstract}

\section{Introduction}

Myomas are the most common tumors of the female genital tract. They are estimated to occur in $20 \%$ to $50 \%$ of women, with increased frequency during the later reproductive years $[1,2]$. There are different management approaches for myomas [3]. Surgical treatments for myomas tend to be invasive and expensive, but they are associated with better quality of life [4]. Operative strategy of myoma is determined according to size, number, and location of the fibroids [5].

For women who need their fertility, despite the introduction of new surgical and non-surgical techniques, open myomectomy remains the most likely treatment option $[2,6]$ as it appears to increase pregnancy rate for these women [1].

There are as many as 8 fibroids removed from a single uterus [7] and there are also reports of successful pregnancies after multiple myomectomies [8]. The aim of this case is to show that multiple fibroids, as many as 36 , can be effectively removed by following meticulous surgical steps of myomectomy.

\section{Case presentation}

26 years old nulliparous mother whose menarche was 12 years back presented with menorrhage of two years. During this period, her menses were coming every 4 to 5 weeks which unusually stayed for 8 to 11 days. She used to change her under wears 4 to 6 times in a day. She had associated lower abdominal pain and noticed abdominal distension since 6 months. Occasionally, she had also urinary frequency and dysuria. She was married 4 years back but did not conceive despite unprotected sexual intercourse.

On examination, her general appearance was good. Vital signs were within the normal ranges. She had pink conjunctiva and nonicteric sclera. Abdominal exam showed abdomino-pelvic mass which was mobile, firm, non-tender and with irregular contour. There were no signs of abdominal fluid collection. The mass moved with cervix on bimanually exam.

Laboratory examination showed Hct of $35.4 \%$, blood group A+, normal urinalysis with negative beta human chorionic gonadotropin, platelet count of 250,000 cells, and normal liver and renal function tests. Semen analysis of her husband was also normal. Abdominal ultrasound index showed multiple myoma.

With the impression of multiple myoma, she was admitted to gynecology ward for myomectomy and also informed on possibility of hysterectomy which was difficult to convince the patient. Two units of $\mathrm{x}$-matched blood were prepared. Intraoperative findings were multiple uterine fibroids (Figure 1) most are intramural, few were submucosal and subserous. Tourniquet with intravenous set was applied at isthmic level (Figure 2). Through midline vertical abdominal and anterior vertical uterine incisions, we removed 36 fibroids (Figure 3). Duration of operation was 2 hours. After the operation, the patient was transfused with two units of blood as her postoperative Hct was $28.5 \%$. She was discharge on $5^{\text {th }}$ post operative day with good condition.

\section{Discussion}

Myoma may be single, but most are multiple. They develop most commonly in the uterine corpus and much less often in the cervix $[3,9,10]$. Our patient had multiple myoma which were located in the uterine corpus.

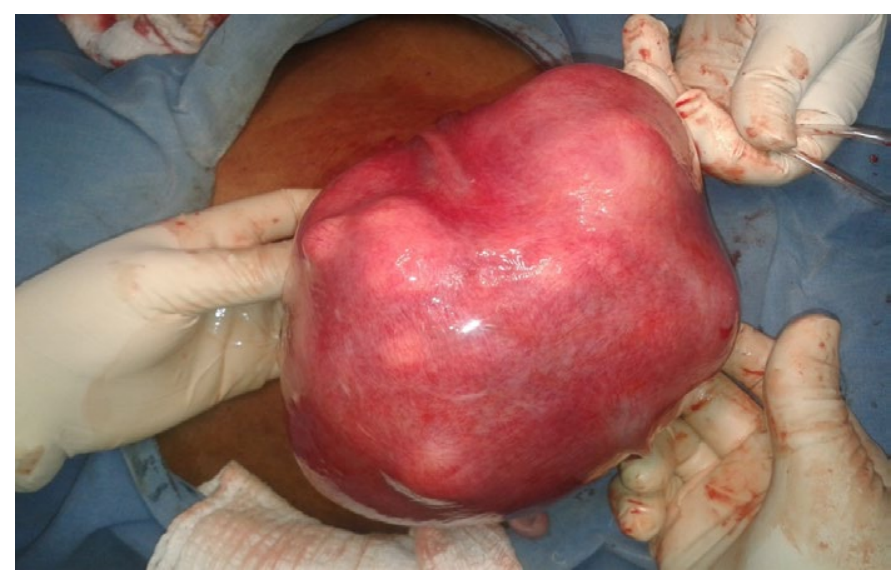

Figure 1. Uterine fibroids of 26 years old patient at Gimbie Adventist Hospital, Gimbi, Ethiopia, January 2015.

Correspondence to: Temesgen Tilahun Bekabil, MD, Assistant Professor of Obstetrics and Gynecology, College of Medical and Health Sciences, Wollega University, Nekemte, Ethiopia, Tel: +251912057186; E-mail: ttamuko@yahoo.com

Key words: multiple fibroids, open myomectomy

Received: February 05, 2015; Accepted: March 06, 2015; Published: March 10 2015 


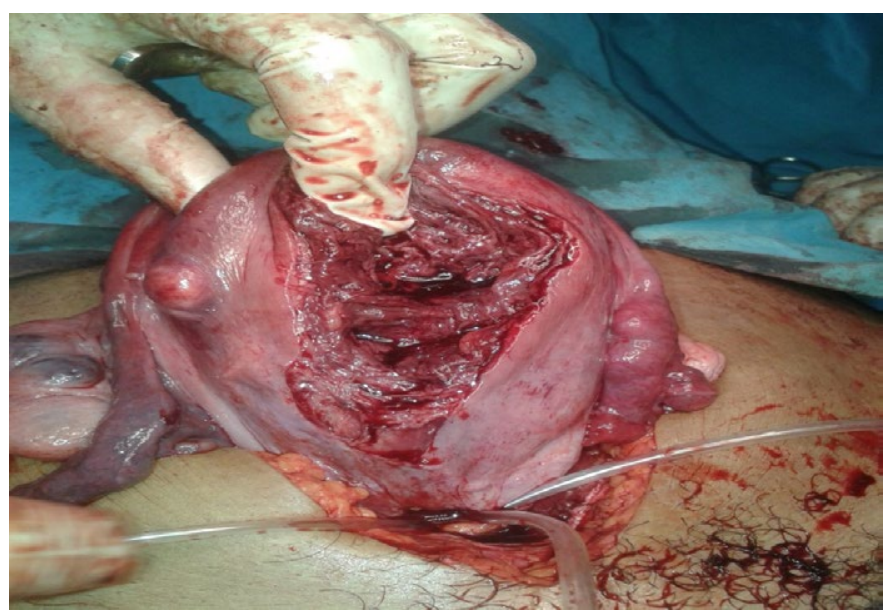

Figure 2. Anterior uterine incision after applying tourniquet to remove multiple fibroids from a uterus of 26 years old patient at Gimbie Adventist Hospital, Gimbi, Ethiopia, January 2015.

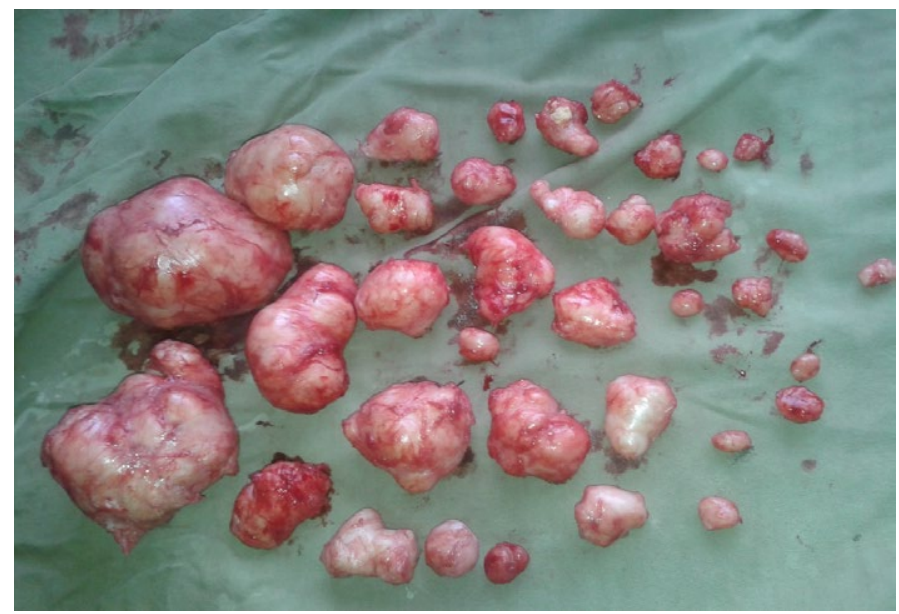

Figure 3. 36 Fibroids removed from a uterus of 26 years old patient at Gimbie Adventist Hospital, Gimbi, Ethiopia, January 2015.

Myomectomy is the surgical removal of fibroids from the uterus, leaving the uterus in place and is the commonest conservative surgical procedure for symptomatic fibroid. Its approach can be an abdominal, laparoscopic, hysteroscopic, or vaginal $[3,10,11]$.

Like other pelvic surgeries, optimum exposure at the operative site is important for myomectomy. Pfannenstiel incision for small uterus and Maylard incision for uterine size that exceeds 12-week sized provides adequate exposure $[3,7,10]$. But in our case, we preferred midline vertical abdominal incision considering the uterine size i.e. 20week sized uterine mass.

As more women delay their childbearing for various reasons, an increasing number of women request conservative surgery for fibroid to preserve their reproductive potential $[3,9]$ as in this case. But sometimes myomectomy may be difficult necessitating hysterectomy in about 1 to $4 \%$ [3] due to some reasons related to their location, size and number of fibroid, and experience of gynecologic surgeon $[5,10]$. This is much feared complication of myomectomy and is devastating both for the patient and attending gynecologist particularly when surgery is meant to improve patient's fertility $[3,9]$. Therefore, it is especially important that patient be informed of the possibility that intraoperative findings may contraindicate myomectomy and require that hysterectomy be performed instead.

There are many cases of successful pregnancies after myomectomies $[1,8]$. Because of this fact, we did myomectomy for our patient.

In this case, even though there were many fibroids in this uterus, we able to remove 36 fibroids successfully. This might be possible through meticulous surgical steps of this procedure and decreasing blood flow to the uterus by taking different measures like use of uterine tourniquet and vasopressin $[3,6,7,9,10]$. Tourniquets are safe and inexpensive to use and can be of great benefit when large or multiple intramural fibroid must be removed as we applied tourniquet in this case.

It is vivid that myomectomies carry various complications [4]. Similarly, our patient required two units of blood transfusion.

\section{Conclusion}

In conclusion, multiple fibroids, as many as 36 , can be effectively removed by following meticulous surgical steps of myomectomy and applying different techniques that decrease blood flow to field of uterine incision or uterus.

\section{Acknowledgment}

The author thanks Gimbie Adventist hospital for allowing him to publish this case report.

\section{References}

1. Machupalli S, Norkus EP, Mukherjee TK, Reilly KD (2013) Abdominal Myomectomy Increases Fertility Outcome. Gynecol Obstet 3: 144.

2. Chen I, Lisonkova S, Joseph KS, Williams C, Yong P, et al. (2014) Laparoscopic versus abdominal myomectomy: practice patterns and health care use in British Columbia. $J$ Obstet Gynaecol Can 36: 817-821. [Crossref]

3. Elizabeth A Stewart. Overview of treatment of uterine leiomyomas (fibroids).up-todate, version 20.3, 2012

4. Chapron C, Fauconnier A, Goffinet F, Bréart G, Dubuisson JB (2002) "Laparoscopic surgery is not inherently dangerous for patients presenting with benign gynaecologic pathology. Results of a meta-analysis," Human Reproduction 17: 1334-1342.

5. Liselotte Mettler, Thoralf Schollmeyer, Andrea Tinelli, Antonio Malvasi, Ibrahim Alkatout (2012) Complications of Uterine Fibroids and Their Management, Surgical Management of Fibroids, Laparoscopy and Hysteroscopy versus Hysterectomy, Haemorrhage, Adhesions, and Complications. Obstetrics and Gynecology International.

6. Taylor A, Sharma M, Tsirkas P, Di Spiezio Sardo A, Setchell M, et al. (2005) Reducing blood loss at open myomectomy using triple tourniquets: A randomised controlled trial. BJOG 112: 340-345. [Crossref]

7. Rossetti A, Sizzi O, Chiarotti F, Florio G (2007) Developments in techniques for laparoscopic myomectomy. JSLS 11: 34-40. [Crossref]

8. Moradan S (2013) Deliveries of four healthy neonates after multiple myomectomies. Zahedan J Res Med Sci (ZJRMS) 15: 93-94.

9. Kunde K, Cortes E, Seed P, Khalaf Y (2009) Evaluation of perioperative morbidity associated with single and multiple myomectomy. J Obstet Gynaecol 29: 737-741. [Crossref]

10. Rock JA, Jones HW (2008) Te Linde's Operative Gynecology, $10^{\text {th }}$ Edition. Section V, Chapter 31-Leiomyomata Uteri and Myomectomy. Lippincott Williams \& Wilkins.

11. Rana A, Gurung G, Amatya A, Khatri R (2007) A simple new technique of performing myomectomy for a predominantly subserosal myoma quickly within few minutes. Kathmandu Univ Med J 5: 110-111. [Crossref]

Copyright: (C2015 Bekabil TT. This is an open-access article distributed under the terms of the Creative Commons Attribution License, which permits unrestricted use, distribution, and reproduction in any medium, provided the original author and source are credited. 